\title{
Smart Instrument Mixes to Deal with Legal but Unhealthy Products and Services: An Economic Approach
}

\author{
Michael FAURE* (iD, Louis VISSCHER** and Franziska WEBER***
}

\begin{abstract}
Many of today's products and services fall into the category of products and services that are, as such, legal but still unhealthy. Think of smoking as an example. This paper deals with the question of which mix of legal instruments should ideally be used in the light of such products and services. It distinguishes between products and services that predominantly lead to "harm to oneself" or "harm to others". In the end, most law and economics arguments point in the direction of ex ante safety regulation. However, when there are concerns about the quality of regulation (eg due to lobbying efforts), liability has important added value. In the "harm to others" scenario, safety regulation is even more warranted because the larger number of victims and the increased difficulty to prove the causal link render litigation burdensome. Strict liability has several advantages over negligence and is, therefore, generally preferred. A strong point of negligence, however, is that it enables the court to conduct its own weighing of costs and benefits, which in specific circumstances may be better than that of the regulator or the producer. Furthermore, it enables the judge to consider not only the harm to the user, but also the harm to others in setting the due care standard.
\end{abstract}

\section{INTRODUCTION}

Increasingly, questions arise concerning the issue of which legal instruments could be used in case particular products and/or services, which are not prohibited, nevertheless create danger or even damage. Of course, this is a rather broad description, as legal products and services can create danger or damage in various different ways. There could just be harm/danger to the users of the product (eg candy bars, crisps and other forms of junk food), although over time such products may also result in higher healthcare costs for others (via insurance premiums). Other products may harm the user but also cause externalities to third parties, such as smoking, which creates damage both to the consumer as well as to third-party bystanders,

* Faculty of Law, Maastricht University, The Netherlands and Erasmus School of Law, Erasmus University Rotterdam, The Netherlands; email: michael.faure@maastrichtuniversity.nl. We are grateful to two anonymous referees for useful comments on a previous draft of this paper.

** Erasmus School of Law, Erasmus University Rotterdam, The Netherlands; email: visscher@law.eur.nl.

**** Erasmus School of Law, Erasmus University Rotterdam, The Netherlands; email: weber@law.eur.nl. re-use, distribution, and reproduction in any medium, provided the original work is properly cited. 
or alcohol, which is unhealthy to the user and also causes losses to others (eg in traffic or cases of (domestic) violence). For some products, the negative externalities may even outweigh the benefits to the consumers if one also looks at human rights, animal welfare, pollution, et cetera. Some of these products are legal in some jurisdictions but not in others (eg weapons that are allowed in the USA but not in most other countries, or soft drugs that are allowed in some countries but not in others). The legality of those products and services is often related to fundamental values and morality in a society, such as respecting consumer choices and freedom, even if that would endanger their health, versus a regulatory prohibition aiming at protection. Even though legal but unhealthy products and services can, therefore, potentially cover a broad variety of products, a common core is that they are allowed in particular jurisdictions even though they can create danger or even damage.

The goal of this article is to examine the appropriate legislative tool to deal with those legal but unhealthy products and services from a law and economics perspective. Throughout the paper, we will distinguish between products and services where "harm to oneself" is predominant and those where "harm to others" is more important. Of course, these two characteristics in essence form the two extremes of a spectrum on which all products and services can be placed. In this paper, for illustrative purposes, we will focus on cases predominantly relating to either "harm to oneself" or "harm to others".

The basis for any legal intervention should be the public interest. The starting point for the economic approach concerning safety regulation is Shavell's important 1984 article in which he addresses the question of whether risks should be controlled via ex ante safety regulation or via ex post liability. ${ }^{1}$ Additionally, within the context of liability law, the question arises as to whether negligence or strict liability would be more suitable for dealing with this issue. We take Shavell's criteria for safety regulation as a starting point and examine the extent to which safety regulation and liability can be considered as either alternatives or complements on the market for unhealthy products or services. Both instruments have advantages and disadvantages, depending upon the specific context and circumstances. The quest is, therefore, to look for a combination of various instruments, a so-called "smart instrument mix".

Our paper contributes to the literature on risk regulation by asking the question of how the law should deal with unhealthy products at both extremes of the spectrum that are nevertheless not banned but allowed. The question of how to deal with products that are as such not banned (and therefore allowed and thus legal) but still create large health risks or even damage has been dealt with in the literature from the perspective of regulation theory. However, the question of how to deal with these products has not been dealt with at a more general level, examining which tools from the regulatory toolbox would be most appropriate. We use the law and economics approach to answer the research question of how the law should deal with legal but unhealthy products and services, and we, importantly, investigate whether the answer also depends on whether the "harm to oneself" or the "harm to others" dimension is prevalent. The framework offered by Shavell (on the choice between liability and

1 S Shavell, "Liability for harm versus regulation of safety" (1984) 13 Journal of Legal Studies 357. 
regulation) provides a useful toolbox for addressing the question of through which legal instruments unhealthy yet allowed services and products can be controlled. However, we equally go beyond Shavell's framework inter alia by addressing the question of why unhealthy yet allowed activities or products should be controlled through legal instruments and by addressing the important question of how incentives for innovation can be provided through various legal and policy instruments. We show that the well-known law and economics methodology can provide useful insights to the policymaker for dealing with this important yet largely unexplored question.

After this introduction, we sketch how smart instrument mixes can be developed (Section II), focusing on the public interest approach concerning the choice between liability rules and regulation (Section II.1), the private interest theory (Section II.2) and the potential role of liability rules in dealing with legal but unhealthy products and services (Section II.3). Finally, we conclude (Section III).

\section{Designing Smart miXes}

\section{The public interest approach}

\section{a. Cost-benefit analysis}

From an economic perspective, the relatively simple criterion for deciding which legal intervention is indicated concerning legal but unhealthy products or services is whether the social costs of the use of these products or services are higher than the social benefits. Of course, other criteria could be employed as well if one were to follow other approaches. A legal intervention could in that case also be based, for example, on the trade-off between, on the one hand, consumer choice and freedom and, on the other hand, the paternalistic need to protect consumers. In this contribution, we employ the law and economics perspective only. One lesson from that perspective is that even if a particular activity may create social costs (such as a health risk), this activity could, from a societal perspective, still be overall desirable on the condition that the total social benefits would outweigh the total social costs of that particular activity. A particular group of citizens could still desire to use these products or services, notwithstanding the inherent health risks related to these items, simply because they increase the utility of these people. This also implies that, from a societal perspective, imposing a general ban on the use of these products or services is not usually considered the best way. It is important to realise that the cost-benefit analysis should be based on social costs and social benefits, not on private costs and private benefits. Here the distinction between "harm to oneself" and "harm to others" is again important. In the former situation, there is only a relatively small difference between private and social costs, which results in fewer reasons to interfere with consumer choice. In the latter situation, however, the gap between private and social costs is much wider, which provides more economic reasons to interfere. Also, on the benefits-side, there can be differences between the private and the social perspective. Some products only provide benefits to the user, whereas others also provide benefits to others (so-called "positive externalities"). An example of this latter situation is vaccination against infectious diseases. The vaccine not only protects the vaccinated 
person, but also contributes to herd immunity, which benefits non-vaccinated people as well. Other pharmaceutical products, on the other hand, only produce private benefits, such as medicines against headache. Both vaccines and other pharmaceutical products may have negative side effects for the user.

As said, many activities create costs not only for the user but also for third parties. Those costs are not borne by the entity creating those costs. This is the issue known in economic theory as the external effect or externality. ${ }^{2}$ This is the case with, for example, smoking or the use of plastic wrapping. The more the costs of production, consumption, disposal, et cetera, are included in the price (which should be increased to include these costs), the more externalities can be internalised. The same holds for the benefits: the more the benefits to others are reflected in the price (which should then, of course, be lowered), the smaller the external effect. As long as the social benefits of an activity are larger than the social costs, it is, from an economic perspective, not desirable to totally ban the particular activity.

If the social costs are higher than the social benefits, first the question arises as to whether the activity can be controlled by taking optimal precautions. If, however, even when taking optimal precautions the social costs would be higher than the social benefits, the activity has to be considered socially undesirable and should, therefore, be controlled. One problem is that there may be a substantial difference between the social costs and benefit calculus and the calculus of private costs and benefits by the entity that creates the risk. As a result, that entity may chose different activity and care levels than are socially optimal. It is particularly in this situation that the law should intervene to internalise externalities. This will result in the risk creator adopting more appropriate activity and care levels.

These first economic considerations lead to a first observation: the mere fact that a product or service can create (health) risks is as such not yet an (economic) argument to prohibit the particular product or activity. It is, however, important to provide incentives to the actor creating the risk to adopt optimal care and activity levels.

\section{b. Safety regulation or liability rules?}

It needs to be determined which instruments can provide appropriate incentives for the actors involved to adopt those optimal care and activity levels, which comes down to trading off the effects of the safety regulation or liability rules. Safety regulation implies that the government ex ante determines a specific care level. ${ }^{3}$ That care level, incorporated in a regulatory standard, subsequently has to be complied with by the risk creator. In a case of non-compliance, administrative or even criminal sanctions can be applied. An alternative is to use the preventative function of tort law. Via an ex post liability suit, tort law can provide the risk creator with ex ante incentives for

\footnotetext{
2 On positive versus negative liabilities and the desirable response from tort law, see G Dari-Mattiacci, "Negative liability" (2009) 38(1) Journal of Legal Studies 21. The external effects for third parties in this particular case are clearly negative as they do create costs for the consumer itself, but potentially also for third parties and for society at large.

3 Usually, a regulation will determine a specific care level, but the government will also refrain from determining an optimal activity level unless an activity is forbidden altogether.
} 
prevention. Which is the appropriate measure in the context of unhealthy products or services?

To answer this question, the four criteria developed by Shavell in his seminal article are of importance. ${ }^{4}$ A first criterion is the availability of information. In particular cases, the government may have better information to determine optimal care levels than the parties involved. The government may have the advantage of being able to use economies of scale. A general governmental assessment avoids every actor individually having to undertake the same research, thereby duplicating efforts and costs. Actors could also lack the necessary incentives to undertake that research themselves. That would especially be the case if the results could be copied by others (eg competitors). It is the well-known free-rider problem that reduces the incentives to innovate.

A second problem is that liability rules only provide incentives to employ an optimal level of care if the insolvency risk can be controlled. If the potential damage is higher than the individual wealth of a risk-taker, liability rules may lose their deterrent effect. The risk-taker will, in that case, consider the accident as one with a maximum value equal to their wealth. The potential injurer cannot lose more than their individual wealth. Under-deterrence may be the consequence. The advantage of safety regulation is that the government can impose a duty on the risk-taker to follow particular care levels that can also be enforced via public sanctions, including non-financial sanctions that are immune to the insolvency risk. ${ }^{5}$

A third criterion concerns the question of the extent to which it is realistic that potentially liable actors would really be confronted with a liability suit. For instance, this may not be the case if the damage is widespread among a large number of victims. The result will be that every individual victim only suffers relatively small losses, as a result of which there are insufficient incentives to file a lawsuit. This is the well-known problem of rational apathy. Problems can also arise if victims have difficulties proving a causal relationship or if there is a long time lapse between the tort and the occurrence of the damage (so-called latency). ${ }^{6}$

A final criterion advanced by Shavell relates to administrative costs. The administrative costs of liability rules are, in comparison to safety regulation, lower. This is the case because in liability law costs only arise if liability suits are really brought, but the preventative function of tort law works even without liability suits being brought. ${ }^{7}$ Settlements are another cost-reducing factor. Safety regulation, to the contrary, always has high costs. ${ }^{8}$ It is costly to set safety standards for all kinds

4 Shavell, supra, note 1.

5 The insolvency risk is obviously an important argument in favour of mandatory solvency guarantees, such as insurance. See inter alia P-J Jost, "Limited liability and the requirement to purchase insurance" (1996) 16 International Review of Law and Economics 259; and MG Faure, "Economic criteria for compulsory insurance" (2006) 31 The Geneva Papers on Risk and Insurance 149.

6 In that context, see also WM Landes and RA Posner, "The private enforcement of law" (1975) 4 Journal of Legal Studies 1.

7 There is substantial empirical research into the preventative function of tort law. For a detailed overview, see D Dewees, D Duff and M Trebilcock, Exploring the Domain of Accident Law. Taking the Facts Seriously (Oxford, Oxford University Press 1996).

8 See Shavell, supra, note 1; and D Wittman, "Prior regulation versus post liability: the choice between input and output monitoring" (1977) 6 Journal of Legal Studies 207. 
of different situations. Moreover, those safety standards also need to be enforced via control and monitoring, and if a violation is established, a sanctioning mechanism has to follow.

\section{c. Application to unhealthy products and services}

When applying those criteria to unhealthy products and services, there are overwhelming reasons for an ex ante approach via safety regulation. First, determining an optimal care level can be complicated for producers. In that respect, it is important to recall that health damage cannot only be caused by large capital-intensive industries with impressive research divisions. Small and medium-sized enterprises (SMEs) can also bring particular products or services to the market that could potentially endanger health. Hence, producers might not behave optimally. As we will argue in more detail in Section II.3, under strict liability the producer decides which care measures to take, so they have to assess the optimal level. Incomplete information may result in incorrect decisions. When a negligence rule applies, the problem may even be worse because there it is not the producer but the judge who will determine the optimal care level. ${ }^{9}$ In practice, judges have even less information than producers and are also not equipped to determine the optimal care level in the case of an unhealthy activity. Precisely because the government can use economies of scale (via governmentfunded research agencies), it could determine the optimal care level in case of unhealthy activities in a collective manner. The result of that research could subsequently be passed on to the market via safety regulation. This result generally holds true for both "harm to oneself" and "harm to others" scenarios with information about the effects on bystanders, for example, being even more difficult to obtain.

An insolvency risk is also realistic in the case of unhealthy products or services, in particular if also affected third parties need to be compensated. Think again of the SMEs. The damage they cause can cost more than the value of the enterprise itself. But even larger enterprises are regularly organised as limited liability companies. This implies that companies can use the limited liability to exercise dangerous activities without being fully exposed to the damage that they may cause. In some cases, risky activities are deliberately incorporated into a company, thus de facto creating an insolvency risk.

In addition, the chance that a liability suit will really be brought in the case of unhealthy activities might be small. The problem may arise that health damage often only appears many years after the harmful activity took place. As a result, in many cases it may be impossible to identify a liable producer. In other cases, it may appear impossible to prove causation. Especially given the long-tail character of health damage and the causation issues, there is a serious risk that liability suits will not be brought, and anticipating this may hamper a preventative effect. The danger of not confronting producers with a liability claim is particularly present in the "harm to others" scenarios. Take the example of passive smoking. There might be many passive smokers, but their harm is more remote and causality more difficulty to prove. Harm

9 See further under Section II.3.c. 
might, furthermore, spread out but become smaller as it spreads out. The smaller the loss per individual victim and/or the more difficult it is to prove causation, the more likely it is that individual victims will refrain from bringing a claim. In other words, they may stay rationally apathetic.

The only counterargument seems to be that ex ante safety regulation is relatively costly to administer compared to liability. However, given the fact that the first three criteria overwhelmingly point to the benefits of safety regulation, the conclusion nevertheless must be that health-threatening activities should primarily be subjected to ex ante safety regulation by the government. This holds even more in the "harm to others" cases than in the "harm to oneself" cases, because of the above-discussed increased challenges for liability where "harm to others" is prevalent. We write "primarily" since the priority of safety regulation does not imply that there would be no more room for the application of liability. However, before we analyse the possible role of liability, we will first briefly discuss the problem that regulation may not always serve the public interest, as we assumed above.

\section{The private interest approach}

Public choice theory has focused attention on the possible influence of private interests in regulation (eg via interest groups that try to "capture" the regulator). The ensuing regulation may then no longer be in the public interest, but may serve the interest of a particular lobby group. That could be a branch of industry representing an important employer in the region, using the argument that government regulation could endanger employment possibilities. For many politicians, this may be a convincing argument. The tobacco and car industry seem appropriate examples. Successful lobbying could prevent regulators from engaging in the necessary research concerning the state of the art or would refrain from issuing restrictive regulations or effective enforcement.

Olson predicted that a lobby group would be successful when the transaction costs for the group to organise itself are relatively low and the information costs for the public at large are high. ${ }^{10}$ Most industry groups (eg the pharmaceutical or chemical industries) are well organised and face relatively low transaction costs. Moreover, the information costs for the public at large to discover the extent to which particular products or services are unhealthy can be quite high.

Becker has indicated that when a counterweight exists for lobbying by industry (eg by non-governmental organisations or consumer groups who represent potential victims), then competition between interest groups may emerge, as a result of which the regulation could be closer to the public interest. ${ }^{11}$ However, if potential victims are insufficiently informed to counter the industry lobby, industry interests may be better represented and regulation may not be in the public interest. Necessary regulation

\footnotetext{
10 M Olson, The Logic of Collective Action: Public Goods and the Theory of Groups (Cambridge, MA, Harvard University Press 1965).

11 GS Becker, "A theory of competition among pressure groups for political influence" (1983) 89 Quarterly Journal of Economics 371.
} 
may then be postponed or include norms that are too lenient. ${ }^{12}$ It can be stressed that, on the victim side, if there are large negative externalities and costs spread to victims that might not even see them coming, their ability to self-organise and "counter-lobby" is obviously limited.

There are several remedies that can be employed to make the interests of the regulator better match the public interest. It has inter alia been suggested that the competences to issue regulation should be granted to different administrative authorities. ${ }^{13}$ In addition, the possibility of launching an appeal against administrative decisions that introduce safety regulation could reduce the risk of lobbying by special interest groups. Furthermore, third parties could be granted the right to ask for a review of regulation and to ask enforcing agencies to inspect specific operators. Even though such measures might increase the effectiveness of safety regulation, they cannot under all circumstances avoid capture, and in addition they have their own costs as well.

In conclusion, safety regulation may be too lenient, may not be effectively enforced or may not even be issued at all. Hence, although from an ideal public interest perspective unhealthy products or services should primarily be controlled via regulation, this may not always work well in practice. The result may be that from a legal perspective particular products or services are "legal" (in the sense that they do not violate a particular safety standard), but they still can create health damage in an inefficient manner. This then opens up the question about the complementary function of liability law, which we discuss in Section II.3.

\section{The potential role of liability rules to control legal but unhealthy products and services}

\section{a. Liability from an economic perspective: prevention and risk spreading}

Whereas many lawyers consider compensation of harm to be the most important goal of liability rules, economists see compensation mainly as a means to serve the goals of prevention and risk spreading. ${ }^{14}$ Liability rules are considered to be instruments that can be employed to internalise negative externalities. They provide incentives to an actor to take optimal preventative measures; that is, measures for which the marginal costs are lower than the marginal benefits (ie the reduction of expected harm). This is the core of the preventative function of liability rules. It corresponds to the simple economic notion that liability has the advantage that it allocates the damage to the

\footnotetext{
12 For empirical research regarding lobbying, see, eg, M Maloney and R McCormick, "A positive theory of environmental quality regulation" (1982) 25 Journal of Law and Economics 99; and B Ruers, Macht en tegenmacht in de Nederlandse asbestregulering (The Hague, Boom Juridische uitgevers 2012).

13 See F Cafaggi and HW Micklitz, "Administrative and judicial enforcement in consumer protection: the way forward" in F Cafaggi and HW Micklitz (eds), New Frontiers of Consumer Protection - The Interplay between Private and Public Enforcement (Cambridge, Intersentia 2009) p 406: "In theory the use of public agencies to monitor and directly sanction would seem to be more effective than separating administrative monitoring from judicial enforcement. But especially in relation to cooperative enforcement, when the enforcer has to conclude agreements with the infringer, the resort to an independent judiciary may ensure transparency and reduce capture. Thus, the greater the use of cooperative enforcement, the more necessary it is to resort to separation between monitoring and enforcement".

14 In that respect, see, eg, G Calabresi, The Costs of Accidents. A Legal and Economic Analysis (5th edn, New Haven, CT, Yale University Press 1977) p 24 ff.; DG Owen, "Deterrence and desert in tort: a comment" (1985) 73 California Law Review 666; and RA Posner, Economic Analysis of Law (6th edn, New York, Aspen Publishers 2003) p 192.
} 
actor that created the risk, so that they internalise that damage. As said, this does not imply that the actor should necessarily ban the activity altogether, nor that they should reduce all damage at all costs. Liability rules will incentivise the actor to follow optimal activity and care levels.

In addition, liability rules can also contribute to loss spreading - both when the liable party is insured against liability and when it is able to spread the loss itself. One can think about an enterprise that would be able to pass on the costs of liability in the prices of products or services, as a result of which the liability costs would be spread over the large community of consumers. ${ }^{15}$ Loss spreading is desirable given the phenomenon of the marginal decreasing utility of money. This implies that the extra utility from one extra euro will be reduced as someone possesses more money. The first euros will be spent on primary needs and are, therefore, worth a lot. As someone has more money, the additional euros are spent on less crucial needs and therefore deliver less utility. This implies that damage of a certain magnitude that has to be carried by one person leads to a loss of more utility than equal damage that is spread over more individuals. Loss spreading, therefore, also contributes to social welfare. ${ }^{16}$

\section{b. Negligence or strict liability?}

At first blush, one could think that a negligence rule is inappropriate, as we refer to legal products that still cause health damage. This raises the question of the extent to which there could be negligence or wrongfulness if bringing the product or the service to the market is as such not illegal. We will argue that the mere fact that an activity is legal does not imply that the negligence rule can no longer play any role. Therefore, we will first explain how law and economics scholars view negligence and strict liability; then we will address relevant differences between both regimes. ${ }^{17}$

From an economic perspective, liability rules are viewed as a system to provide desirable behavioural incentives. This concerns incentives to follow optimal care and activity levels. The more care an actor takes in the exercise of a particular activity, the more the expected damage will decrease. However, a higher care level also creates higher costs of prevention. As long as the marginal costs of more preventative efforts are lower than the marginal benefits thereof (in the sense of a decrease in expected damage), it is desirable that those extra preventative efforts are taken. When the marginal costs of care, however, become higher than the marginal benefits, the additional preventative efforts are no longer desirable. The turning point is referred to as the optimal care level.

The crucial difference between negligence and strict liability from an economic perspective is the following: under negligence, a particular level of care will be

15 The degree to which this loss spreading via the price is possible differs between the "loss to oneself" and the "loss to others" scenarios. The more the losses are suffered by others than the direct consumers, the less they can be included in the price of the product or service.

16 See Calabresi, supra, note 14; and SP Croley and JD Hanson, "The non-pecuniary costs of accidents: pain and suffering damages in tort law" (1995) 108 Harvard Law Review 1822.

17 For more details, see S Shavell, "Strict liability versus negligence" (1980) 9 Journal of Legal Studies 1; and H-B Schäfer and F Müller-Langer, "Strict liability versus negligence" in M Faure (ed.), Tort Law and Economics, Vol. 1, Encyclopedia of Law and Economics (2nd edn, Cheltenham, Edward Elgar 2009) p 3. 
determined as the due care level. When the potential injurer follows that due care level, they will not be held liable. If, on the contrary, they follow a lower care level, there will be liability. Ideally, the due care level required by the legal system would equal the optimal care level. In that case, actors would be incentivised to make a socially desirable decision concerning the costs and benefits of additional care. This implies that under a negligence regime the mere fact that there is harm does not mean that there is negligence. The optimal care level is found by weighing the marginal costs of prevention and marginal benefits. Generally speaking, at this optimal care level there will still be accidents and, hence, damage. Further reducing the expected damage beyond the optimal care level would lead to higher marginal costs compared to the marginal benefits. For example, in theory, all deadly traffic accidents could be avoided by introducing a maximum 'speed of ten kilometres an hour on highways and enforcing that as well. Such a preventative measure would, however, be considered to be too expensive. The mere fact that a traffic accident leads to a fatal incident does not mean that there is negligence on the part of the injurer. Even if optimal care levels are followed, fatal accidents can still take place. When the potential injurer followed the optimal care level and nevertheless damage occurred, under a negligence regime the victim will have to bear the damage themself. This may lead to a demand for insurance. ${ }^{18}$ The due care level required from the potential injurer will, within the framework of the application of the negligence rule, be determined by the judge. Strict liability works in a fundamentally different way: as soon as there is a causal relationship between the behaviour of the injurer and the damage, the injurer is bound to compensate, irrespective of their care level. This implies that, under strict liability, it is the potential injurer themself who determines how much care they take. Under negligence, it is in principle the judge who determines the duty of care. ${ }^{19}$ This important difference, of course, has consequences for determining the different characteristics of negligence and strict liability.

There are several factors that determine whether negligence or strict liability is better suited to providing the desirable incentives. The first factor is information costs. It is possible that, in fixing the due care level, mistakes are made due to information problems. As a consequence, the due care level required by the judge (under negligence) or the care level chosen by the injurer (under strict liability) may deviate from the optimal care level. If the judge has the best information to determine optimal care levels, then negligence may be the optimal rule. If, to the contrary, the potential injurer is better placed to weigh marginal costs and marginal benefits, then strict liability is more appropriate. The weighing of those costs and benefits should ideally be done by the actor who possesses the best information. ${ }^{20}$

\footnotetext{
A full discussion about the role of insurance lies beyond the scope of this paper.

19 Although, as we will explain below, the judge will in many cases be assisted by the legislator, as a violation of safety regulation will in many legal systems be considered a violation of the due care standard. See below Section II.3.c(1).

20 WM Landes and RA Posner, The Economic Structure of Tort Law (Cambridge, MA, Harvard University Press 1987) p 65 ff.; S Shavell, Foundations of Economic Analysis of Law (Cambridge, MA, The Bellknap Press of Harvard University Press 2004) pp 18 and 188.
} 
The second relevant factor for choosing between negligence and strict liability is the activity level. It is desirable that an activity is only exercised when it provides more benefits than costs. When a particular actor does not have to carry all of the costs of their activity, there is a danger that they will adopt a too-high activity level. An injurer will only take an optimal activity level under strict liability, because they bear the full costs of the activity. Under a negligence rule, the potential injurer is freed from liability if they follow the due care level, so they do not bear the expected accident losses and, hence, will choose a too-high activity level. The potential victim, on the other hand, will adopt a too-high activity level under strict liability, since in that case the injurer will be liable to compensate all damage. It is not possible to formulate liability rules that provide incentives to follow optimal activity levels for both the injurer and the victim. ${ }^{21}$

The third factor is dimensions of care. Liability rules not only provide behavioural incentives for features of care that are observable and can be controlled. An advantage of strict liability is that it incentivises the potential injurer to take all possible measures into account as far as they can optimally reduce the accident risk, whether those dimensions are observable or not. As strict liability forces the potential injurer to compensate all damage, they will take all efficient measures to reduce the accident risk. Under negligence, to the contrary, the potential injurer will only take into account the measures of care incorporated in the due care level (ie those elements of the duty of care that can be observed and controlled by the judge).

The fourth factor is insolvency. Strict liability may create more problems in case of insolvency than negligence. The reason for this is that, under strict liability, there is under-deterrence as soon as the total damage is higher than the wealth of the potential injurer. Under negligence, a potential injurer will still take due care as long as the costs for taking due care are lower than their individual wealth. Following the legally required due care level is still a way for the potential injurer to avoid liability. ${ }^{22}$ The insolvency risk under strict liability can be remedied by accompanying it by another mechanism; for example, by imposing a duty on the actor to provide solvency guarantees (eg mandatory liability insurance).

The fifth factor is loss spreading. Under strict liability, it is the injurer who compensates the entire damage; under negligence, the loss remains with the victim. Depending upon who can better spread the loss, this may give an advantage for one of the two rules.

The last factor is administrative costs. Negligence is relatively complex as it requires the duty of care to be determined, as well as whether the injurer violated that duty of care and whether they can be blamed for that violation. Strict liability, on the other hand, does not require these difficult assessments, but can lead to more court cases as victims only

21 See Shavell, supra, note 17, 2; Landes and Posner, supra, note 20, 61; Posner, supra, note 14, 177; and Shavell, supra, note 20, 193.

22 This difference between negligence and strict liability disappears when, under negligence, a causal relationship is required between the unlawfulness of the behaviour and the damage, as was claimed by M Kahan, "Causation and the incentives to take care under the negligence rule" (1989) 18 Journal of Legal Studies 427; and LT Visscher, "Wrongfulness as a necessary cause of the losses - removing an alleged difference between strict liability and negligence" (2011) 2 Economic Analysis of Law Review $194 \mathrm{ff}$. 
have to prove that the behaviour of the defendant caused their loss, not that any violation of a due care standard took place. Generally, law and economics scholars hold that strict liability will result in lower administrative costs, as the outcome of such cases is more predictable and will therefore result in (cheaper) settlements and in fewer tort cases. ${ }^{23}$

When applying these criteria to the case of unhealthy products or services, strict liability prevails. An advantage of strict liability is that the potential injurer (a producer of particular products or a provider of services) may have better possibilities of loss spreading than the victim. They will have the possibility to pass on the damage to all consumers via the price of the product. As was indicated in Section I, the broad concept of legal but unhealthy products and services may, in practice, cover a wide variety of different situations. However, none of the situations would be such that, for example, the risk would be created by an occasional nonprofessional (private) manufacturer (in which case there may also be an argument in favour of a negligence rule). Most of the cases that we envisage here (eg tobacco manufacturing) concern professional producers. Those will, as repeat players, have better information on the products and services that they bring to the market than the judge. This makes strict liability even more attractive. The argument may, of course, be stronger when damage is caused by large, well-equipped multinationals rather than by SMEs. The advantage of strict liability becomes even stronger when dimensions of care play a role that cannot easily be controlled by external parties such as a judge. This may especially be an issue in the case of services. In addition, the better activity level and the lower administrative costs are arguments in favour of strict liability.

It is important to add a defence of contributory negligence to the strict liability rule in order to also provide incentives to follow efficient care levels for the potential victim. In some cases, there may even be an information advantage on the side of the victim. The victim may know particular features of themself that may make them refrain from the use of a particular product or service. Someone with a weak back should not be able to hold the organiser of a bungee-jumping event liable for damages as a result of increased back pain after the jump. In such an example, the victim is clearly the cheapest cost avoider who can avoid the damage by not engaging in that activity in the first place. In some cases, the defence of assumption of risk could apply. This would be an issue for individuals who started smoking at a time when the dangers of smoking were general knowledge and who subsequently would wish to file a lawsuit against a tobacco producer.

The above-described framework is based on "harm to oneself" situations because it considers a producer vis-à-vis the consumers who suffer losses. A more nuanced look is necessary for the "harm to others" cases: in these cases, as we have explained above, it is doubtful whether the "harmed others" will start a lawsuit in the first place. Under strict liability, such a "low probability of being held liable" may result in the producer taking less care than is optimal, because they do not incorporate the "losses to others" if those others will not sue. Under negligence, on the other hand, the court could base the due care standard on the full losses; that is, the "harm to oneself" of the consumers and the "harm to others" of bystanders. If producers would

23 Calabresi, supra, note 14, 28; and Shavell, supra, note 20, 282-83. 
indeed take this due care level, the outcome would be better than under strict liability where they take too little care. In order for the producers to be induced to take this due care level under negligence, the costs of taking due care have to be lower than the expected liability when not taking due care. This will only be the case if the fraction of "harm to oneself" cases is large enough to create enough expected liability to make it worthwhile to take due care. So, in extreme situations with (almost) no "harm to oneself", neither strict liability nor negligence will work, because not enough lawsuits will be filed. In somewhat less extreme cases, negligence may already provide enough incentives to take optimal care if due care is set at the optimal level and expected liability arising out of the cases filed by consumers outweighs the costs of taking due care. Strict liability only provides the correct incentives if all losses (ie "harm to oneself" and "harm to others") are included in expected liability.

\section{c. Liability and safety regulation}

(1) Interdependencies in the light of good and bad regulation. It has already been mentioned that negative externalities can be internalised via both ex ante safety regulation and ex post liability rules. If the regulator has better information than the parties, it may be desirable for this information to be incorporated into regulations to incentivise the actors involved to show optimal behaviour. The intervention of the regulator can also benefit from scale economies. If the regulator has correctly weighed marginal costs and benefits, it makes a lot of sense to consider every violation of regulation automatically a fault. In that case there would no longer be a "legal activity" as there would be a violation of regulation. This could lead to an interesting interdependency: the victim uses the (violation of) regulation to support their liability claim, and at the same time the victim becomes a private enforcer of regulation. This could constitute an optimal mix between liability and regulation.

It is, however, also possible that the regulator did not correctly determine the optimal care level. This could be caused by a lack of information or by the influence of interest groups on the regulation, but also because the regulation did not take into account that specific circumstances may call for a different standard or simply because regulation has meanwhile become outdated. Government (via taxation) may generate substantial income from the use of unhealthy products such as alcohol or tobacco. Strict liability ensures liability even in the light of lawful acts. A major advantage of strict liability is that no violation of a duty of care has to be proven. Under strict liability, the question of whether the particular product or service is legal, therefore, in essence becomes irrelevant. Despite the overall strong arguments in favour of strict liability, there might still be a role for negligence in the overall mix. ${ }^{24}$ In the light of suboptimal regulation, a negligence regime could be applied as well. The advantage is that in this case the judge, who is less vulnerable to lobbying by interest groups, would determine the regulatory standard. The judge can incorporate elements that the regulator did not sufficiently take into account. This could imply that the producer

\footnotetext{
24 Besides the fact that a successful lobby may frustrate the introduction of strict liability so that negligence is the only available liability regime.
} 
followed the regulation but that the judge nevertheless holds the producer liable. In that case, negligence liability would apply for legal products or services. The regulation then becomes a rather minimal standard for an average situation. ${ }^{25}$ If the concrete factual situation varies or if the minimum standard is too low, there can still be liability under the negligence regime. ${ }^{26}$ This could equally be considered an interesting interdependency between liability and regulation. ${ }^{27}$ Such a regime provides an important signal to industry: it does not suffice to merely follow (weak, inefficient or outdated) government regulation. As the deterrent function of liability rules still applies, actors also have to follow the duty of care required under the negligence regime. An example of this is a liability case against the producers of so-called bump stocks, initiated by victims and their descendants after a shooting in Las Vegas on 1 October 2017. These are legal devices allowing semi-automatic weapons to be used as an (illegal) automatic weapon. The victims blame the producers for negligent behaviour. It is quite possible that the regulation allowing those bump stocks has been the result of the powerful weapons lobby in the USA. ${ }^{28}$ In December 2018, the US Department of Justice issued a final rule, and since March 2019 bump stocks have been illegal for almost all US civilians. Various polls suggest that since the Las Vegas shooting, 70-80\% of registered voters support a bump stock ban. ${ }^{29}$ Liability could thus fulfil an important supplementary role, ultimately typically resulting in new regulation.

The incentives provided by liability law can thus constitute an important correction for the relatively static character of safety regulation and for the possible effects of lobbying on regulation. Liability rules are more flexible and can therefore adapt due care standards in a dynamic manner, and also take into account technological developments. An exposure to liability can equally reduce the effectiveness of lobbying.

The question of the effects of not following regulation for civil liability is more complex from an economic perspective. The starting point should be (and this is also the position taken by Shavell) that non-compliance with regulation should not necessarily imply that there should be civil liability. ${ }^{30}$ After all, it is possible that in the particular circumstances of the case, this specific injurer may have higher care costs or lower care benefits than the legislator assumed. In that case, there are two possibilities. The first possibility is that the assessment made by the legislator would

\footnotetext{
25 Notice that the concept of regulator should, of course, be interpreted broadly, as risk regulation is in practice usually not issued by the formal legislator but rather (via delegation) by administrative authorities. However, the danger of lobbying and capturing is as realistic for the case of the regulator as it is for the administrative agency.

26 See S Rose-Ackerman, "Regulation and the law of tort" (1991) 81 American Economic Review, Papers and Proceedings 54.

27 See CD Kolstad, TS Ulen and GV Johnson, “Expost liability for harm versus ex ante safety regulation: substitutes or complements?" (1990) 80 American Economic Review 888; and P Burrows, "Combining regulation and legal liability for the control of external costs" (1999) 19 International Review of Law and Economics 227.

28 By the so-called National Rifle Association (NRA). See <https://home.nra.org > (last accessed 18 May 2021).

29 M Sanger-Katz and Q Bui, "A bump stock ban is popular with the public", The New York Times, 12 October 2017; A Khalid, "NPR poll: after Parkland, number of Americans who want gun restrictions grows", National Public Radio, morning edition, 2 March 2018. Various gun right groups have challenged the restrictive legislation: see, eg, G Martin, "Gun lobby files lawsuit challenging Trump's bump stock ban", Las Vegas Review - Journal, 27 December 2018; and D Holden, "Gun rights activists are already suing over Trump's bump stock ban", BuzzFeed News Reporter, 18 December 2018.

30 Shavell, supra, note 1, 365-66.
} 
not be sufficiently geared towards the specific case, as a result of which a finding of liability should not necessarily follow. However, the information costs for the judge to determine whether an "individually" optimal care level was followed can be extremely high. In many legal systems non-compliance with regulation (often in some cases even automatically) leads to liability. The second possibility is that there is an inefficient injurer who had no possibility to efficiently follow the care level required by the regulator. In that case, holding the operator to the regulatory standard has the advantage that it forces the operator to choose another activity. In sum, in both situations the advantage of this automatic rule is that it reduces the information costs for the judge and therefore also the administrative costs of applying the tort system.

(2) Instruments beyond safety regulation and liability rules. Aside from the traditional mechanisms discussed by Shavell, other mechanisms might feature in an optimal legal response to the use of legal but unhealthy products and services. As said, liability rules do reach their limit in the case of insolvency of the injurer. ${ }^{31}$ As long as the actor follows the conditions imposed by public safety regulation, no public sanctions will be employed. Public enforcement is therefore less sensitive to the insolvency risk. Public enforcement equally has the advantage that it has particular (non-financial) sanctions, such as the possibility to withdraw a permit, which can be highly deterrent. ${ }^{32}$ However, also within private law, there are some non-monetary sanctions. When an insolvency risk exists, injunctions may be more effective remedies. In that case, the judge could prohibit the producer from bringing unhealthy products to the market. This may potentially have a large deterrent effect. ${ }^{33}$ Hence, to some extent, a deterrent effect can even be upheld by private enforcement.

In some cases, it will be necessary to resort to criminal law. The advantage of criminal law is that more varied sanctions can be applied than in the case of private enforcement. Moreover, criminal law allows the application of non-monetary sanctions, more specifically imprisonment. The major advantage of this sanction is that it can still have a deterrent effect, as in the case of insolvency. ${ }^{34}$ Imprisonment can be an important deterrent in the case of a low probability of detection and high insolvency risk. ${ }^{35}$ In those conditions, only criminal law can provide deterrence.

When it comes to the rational apathy problem, there are likewise some solutions imaginable beyond public enforcement. When private enforcement fails because the damage to each individual victim is limited, collective action could be a remedy. ${ }^{36}$

\footnotetext{
31 Shavell, supra, note 20, 473.

32 See MG Faure, AI Ogus and NJ Philipsen, "Curbing consumer financial losses: the economics of regulatory enforcement" (2009) 31(2) Law \& Policy 178: particular administrative sanctions such as the withdrawal of a permit can lead to a higher deterrent effect than imprisonment.

33 ibid, 176; and AI Ogus and LT Visscher, "A law and economics perspective on injunctive relief" (2010) 17 Maastricht Journal of European and Comparative Law 32.

34 See R Bowles, M Faure and N Garoupa, "The scope of criminal law and criminal sanctions: an economic view and policy implications" (2008) 35 Journal of Law and Society 402; S Shavell, "Criminal law and the optimal use of non-monetary sanctions as a deterrent" (1985) 85 Columbia Law Review 1247; and Shavell, supra, note 20, 544.

35 Bowles et al, supra, note 34, 405.

36 See, eg, MG Faure and LT Visscher, "Mass damages in the Netherlands: to collect or not to collect, that is the question" in M Faure, W Schreuders and LT Visscher (eds), Don't Take It Seriously. Essays in Law and Economics in Honour of Roger Van den Bergh (Cambridge, Intersentia 2018) p 389.
} 
This usually also leads to a reduction of the costs for each individual participant in comparison to the case where separate procedures might be launched. This is of particular interest in the "harm to others" scenarios. Collective action could solve free-rider problems. Especially in cases of widespread damage (mass damage), a freeriding problem may arise. In some cases, the victim will simply wait to see whether others launch a procedure. If these others eventually reach a positive result, the victim will free ride on the efforts of others. The guideline, no matter how the mix is ultimately assembled, remains that the potential injurer has to be aware of the fact that they face the consequences of their actions. Only in that particular case will a preventative effect generate sufficient incentives to invest in optimal care levels.

One possibility for reducing the costs of public enforcement is to shift the responsibility to the market participants. This could imply that they, for example, employ internal compliance mechanisms focused on guaranteeing the compliance with regulation. In this scenario, the role of monitoring changes. The primary importance then becomes verifying the internal compliance mechanism installed by the company or reacting if complaints were still filed.

Finally, we should also point out the possibility of employing self-regulation. The law and economics literature has highlighted the fact that self-regulation has the advantage that companies often have better information than the government. ${ }^{37}$ Self-regulation, of course, also entails the risk of capture. Some even qualify self-regulation as "the ultimate form of regulatory capture", as it will ultimately be the industry itself that will dictate the norms with which it will comply. ${ }^{38}$ Self-regulation can therefore never be a free-standing instrument. It has to be combined with monitoring in order to provide adequate incentives for compliance with the (self-)regulation. ${ }^{39}$

(3) Intermediate conclusion. Overall, a balanced picture is required, and the conclusion inevitably is that safety regulation, liability rules and possibly even more mechanisms need to be combined. Regulators may often have an information advantage, but they also need to use that information advantage. Public choice theory tells us that guarantees have to be introduced to ensure that the regulator and enforcement authorities effectively act in the public interest. But remedies against private interest regulation further increase the costs of regulation. For all of those reasons, the supplementary role of liability rules remains important. The major advantage, as already indicated, is that liability rules can also be applied against a potential injurer when public regulation as a result of lobbying does not provide optimal results. The case for civil liability is less strong for the "harm to others" scenarios due to issues such as rational apathy, information asymmetry, et cetera. Strict liability will be favoured (with the possible exception of cases at the "harm to others" end of the spectrum), as it entails a large number of advantages for the case of legal but unhealthy products and services. The negligence rule can play an important role,

\footnotetext{
37 S Keske, Group Litigation in European Competition Law: A Law and Economics Perspective (Cambridge, Intersentia 2010); and AI Ogus, "Rethinking self-regulation" (1995) 15 Oxford Journal of Legal Studies 97.

38 FH Stephen and JH Love, "Regulation of the profession" in B Bouckaert and G De Geest (eds), Encyclopedia of Law and Economics, Vol. III, The Regulation of Contracts (Cheltenham, Edward Elgar 2000) p 990.

39 JC Miller III, "The FTC and voluntary standards: maximizing the net benefits of self-regulation" (1985) 4 Cato Journal 903.
} 
especially in combination with regulation when the norm drafted by the regulator does not fit well with the specific circumstances or when "harm to others" dominates. In that case, the judge can determine optimal care levels on the basis of a cost-benefit analysis of all relevant costs and benefits.

\section{d. Incentives for innovation}

One aspect that Shavell does not deal with in his general discussion concerning the economics of accident law is that liability rules can also affect incentives to innovate. This is especially of interest in the case of products with known health risks that can be reduced via supplementary research. It could also play a role in the case of unknown health risks. Social welfare can be increased when the social costs related to products or services are reduced in the long run. The extent to which liability rules provide incentives to undertake research into (especially unknown) risks and to innovate is therefore an important criterion for determining whether liability rules or regulation are the most suited instrument.

If liability rules free producers as long as they follow the existing safety regulation or the legally required due care standard, producers will lack any incentive to undertake supplementary research into safety risks. Those incentives for innovation can only be provided if producers are to some extent held liable for those negative externalities.

If a new product appears on the market, it is possible that the related health risks will not be fully known. It is possible that the long-term effects may not have been sufficiently studied and analysed. A liability for unknown risks can increase the so-called "state of the art" as far as technology is concerned. A condition is, of course, that the potential injurer is able to exercise that research or at least is able to hire someone to do that research for them. ${ }^{40}$ Finsinger and Simon write in this regard related to their analysis of the development risk defence within the framework of product liability: "History teaches that it is the firms who first collect hints, and then acquire evidence of such risks. ... Producers first learn about development risks". 41

As far as the incentives are concerned, a distinction should again be made between strict liability and negligence. Under strict liability, engaging in supplementary research has two advantages for the potential injurer:

- If the research shows that the activity is less dangerous than previously thought, the injurer can manage with a lower level of care. The expected value of this advantage consists of the probability that the activity turns out to be less dangerous multiplied with the savings in prevention costs, as now less care has to be taken.

- If the research shows that the activity is more dangerous than previously thought, the actor will take more care. As a result, the primary accident costs (consisting of the costs of prevention and the expected damage) reduce as, under the old (lower) care

40 S Shavell, "Liability and the incentive to obtain information about risk" (1992) 21 Journal of Legal Studies 259; and H-B Schäfer and C Ott, Lehrbuch der ökonomischen Analyse des Zivilrechts (Berlin, Springer 2012) p 240.

41 J Finsinger and J Simon, "An economic assessment of the EC Product Liability Directive and the product liability law of the Federal Republic of Germany" in M Faure and R Van den Bergh (eds), Essays in Law and Economics. Corporations, Accident Prevention and Compensation for Losses (Antwerp, MAKLU 1989) p 196. 
level, too much damage was caused. The expected value of that benefit therefore includes the likelihood that the activity will be more dangerous multiplied with the reduction in primary accident costs as a consequence of the higher level of care.

If those two benefits together are higher than the costs of research, this implies that the producer concerned will effectively engage in the research. This is also a socially desirable consequence. In the case of strict liability, there is no difference between the private benefits and the social benefits, since the potential injurer bears all of the costs but also enjoys all of the benefits of supplementary research. Therefore, the potential injurer will take a socially desirable decision concerning additional research.

Under negligence, a problem may arise: if the potential injurer is only considered negligent if they take less than due care, then, given the information they have, they will receive insufficient incentives to innovate. If, on the basis of new information, the injurer establishes that the activity is less dangerous than they first thought, they will reduce their care level, which is socially desirable (as was the case under strict liability). If, however, they discovered that their activity is more dangerous than they first thought, they would have to increase their care level. This is desirable from a social perspective since the reduction in expected accident costs is larger than the increase in care costs. However, it does lead to an increase in the private costs of care, which the potential injurer could have prevented by not engaging in additional research. From this, it follows that the private benefits of information are lower than the social benefits. There can therefore be situations where the social benefits of information are higher than the information costs but the private benefits are not. In those circumstances, the potential injurers do not receive sufficient incentives to engage in the necessary research. This problem does not arise if the judge, in determining the due care level, does not examine what the injurer knew, but what they had to know. In other words, the negligence rule should be interpreted in such a way that an actor is only liable if they take less care than optimal, assuming an optimal collection of information. In that case, the private and social benefits become equal again.

If following safety regulations is a full defence in a liability claim, the same problem arises as in a case of a negligence rule that only examines what the injurer knew and not what they should have known. This implies that a rightly structured negligence rule can fulfil an important role in supplementing safety regulation. One has to avoid the situation that producers, who do their own additional research, create their own liability when they suddenly discover that their products or services are more dangerous than they originally thought. The latter could obviously reduce the incentives to engage in supplementary research. Therefore, the duty of care under negligence should be fixed according to what producers should know. This constitutes an important argument in favour of a so-called development risk defence. This defence avoids the situation where producers either do not engage in any research or do not publish the results of that research (if it was not advantageous to them). If the research costs of finding out unknown risks are higher than the previously mentioned advantages related to the adaptation of the care level and the new information, the potential injurer does not have to know the specific danger. Excluding liability for such a development risk 
would again align the private costs and benefits of research better with the social costs and benefits.

A smart liability system should create efficient incentives for engaging in subsequent research in combination with effective safety regulation. One of the possibilities for such a smart mix is that a producer would generate information on new risks, which they could subsequently share with public control agencies on the condition of (partial) immunity against liability for old cases.

\section{Concluding Remarks}

The question of whether there should be liability for the use of legal but unhealthy products or services gives rise to many interesting yet largely unexplored questions from a law and economics perspective. Using the so-called public interest approach as a starting point, it could be argued that if the regulator was fully informed and made regulation in the public interest, these types of situations would in principle not exist or be highly exceptional. The application of Shavell's criteria for safety regulation clearly points to the superiority of ex ante safety regulation by the government. This would imply that the government would collectively determine the required care level for unhealthy activities and would transpose this in a standard regulation. The problem, however, is that for manifold reasons optimal safety regulation is not always issued (eg due to a lack of information or lobbying by industrial interest groups). This explains why unhealthy products or services often still remain allowed and thus formally legal. Therefore, it is important to internalise the negative externalities related to those products and services via the supplementary deterrence provided through liability rules. In the "harm to others" scenario, safety regulation is even more warranted than in the "harm to oneself" scenario because the larger number of victims and the increased difficulty of proving the causal link render litigation burdensome. The law and economics literature, furthermore, points to the great advantages of strict liability over negligence rules, but we have relativised these advantages for situations where "harm to others" dominates.

The optimal mix, therefore, primarily needs to consist of a combination of safety regulation as the primary instrument supplemented by the deterrent function of strict liability. One advantage is that no violation of a duty of care is necessary for strict liability, as a result of which liability can also arise in the case of lawful acts. The advantage might be fully realised when government regulation becomes outdated or for other reasons not fully optimal. In that case, the judge will be allowed to make their own assessment of the costs and benefits of specific care measures related to the specific concrete circumstances of the case. The reason for this is that, in the case of strict liability, the weighing of marginal costs and marginal benefits is done by the injurer. Liability follows automatically if the victim can prove that their harm was caused by the injurer's activity. In cases of bad regulation, a role can furthermore be envisaged for negligence rules, as the judge will carry out their own less biased cost-benefit analysis when deciding a case. 
Another parameter that needs to be fine-tuned is that liability rules should be shaped in such a way that they also provide optimal incentives for innovation. Again, strict liability fares well. It has the advantage that the private costs of the injurer are equal to the total social costs of accidents. As a result, optimal incentives are provided to the producer, or potential injurer, to invest in research into all optimal ways of reducing the accident risk.

Of course, as was indicated in Section I, the case of legal but unhealthy products or services may cover a wide variety of different situations, and the differentiation made between "harm to oneself" and "harm to others" scenarios was helpful for exemplifying extreme cases. In reality, many products and services will lead to harm to both users and third parties in varying degrees. In addition, the extent to which positive externalities emerge differs per case. It would be interesting to address those different types of situations in more detail in further research. 